\title{
NÍVEIS DE DESEMPENHO EM MATEMÁTICA DE ESCOLAS ESTADUAIS DO MUNICÍPIO DE MOGI MIRIM - SP
}

\section{ARTIGO ORIGINAL}

CAMPOS, Marco Antonio ${ }^{1}$

CAMPOS, Marco Antonio. Níveis de desempenho em matemática de Escolas Estaduais do Município de Mogi Mirim - SP. Revista Científica Multidisciplinar Núcleo do Conhecimento. Ano 05, Ed. 11, Vol. 03, pp. 79-90. Novembro de 2020. ISSN: 2448-0959,

Link de acesso:https://www.nucleodoconhecimento.com.br/educacao/escolas-estaduais

\section{RESUMO}

O desempenho na disciplina de Matemática dos alunos das escolas públicas do estado de São Paulo é medido através da avaliação do Saresp aplicado ao final de cada ciclo escolar. Com isso classificam-se os alunos em quatro níveis de desempenho "Abaixo do básico", "Básico" "Adequado" e "Avançado" conforme critérios e pontuação estipulados pela secretaria estadual de educação paulista. Com base na publicação destes níveis de desempenho foram analisadas quatro escolas estaduais do município de Mogi Mirim-SP, pertencentes a Diretoria de Ensino de Mogi Mirim, entre os anos de 2014 a 2018 na disciplina de Matemática no $9^{\circ}$ Ano do Ensino Fundamental e na $3^{\circ}$ Série do Ensino Médio. Os resultados mostram que a aprendizagem está aquém do almejado para os alunos que estão encerrando um ciclo escolar. Portanto, junto com a análise destes resultados apresentam-se questionamentos e potencialidades destes fatores comprometedores da aprendizagem em relação a gestão, corpos docente e discente e comunidade escolar.

\footnotetext{
${ }^{1}$ Graduado em Ciências - Matemática e em Engenharia Civil. Pós-graduando em Gestão Escolar.
} 
Palavras-Chave: Desempenho Escolar, Saresp, desempenho educacional, educação pública, matemática.

\section{INTRODUÇÃO}

A educação pública do estado de São Paulo tem seu resultado pautado em índices de desempenho padronizados pela Secretaria Estadual de Educação, atual SeducSP. Atualmente as disciplinas de Língua Portuguesa e Matemática recebem ao menos quatro avaliações de desempenho, para todos os anos dos Ensinos Fundamental e Médio: ADE - Avaliação Diagnóstica de Entrada, aplicada nas primeiras semanas de aula, com o conteúdo do ano anterior, e ao final do $1^{\circ}, 2^{\circ}$ e $3^{\circ}$ bimestres são aplicadas as AAP: Avalição da Aprendizagem em Processo, com o conteúdo das Sequências Didáticas do currículo destas disciplinas.

Estas avaliações, ADE e AAP, são avaliações elaboradas pela Seduc-SP e padronizadas e iguais para toda a rede. Por exemplo, todos os alunos do $9^{\circ}$ Ano do Ensino Fundamental fazem, em um período determinado pela Seduc-SP, a mesma prova AAP do $1^{\circ}$ bimestre de Matemática.

A aplicação destas avaliações, além de verificar o desenvolvimento da turma e identificar as potenciais falhas de ensino / aprendizagem ao longo do percurso, tornase um treinamento maior para outras avaliações externas e principalmente para o Saresp - Sistema de Avaliação de Rendimento Escolar do Estado de São Paulo, avaliação anual aplicada ao final de cada ciclo, $5^{\circ}$ e $9^{\circ}$ Anos do Ensino Fundamental e $3^{\circ}$ Série do Ensino Médio.

Com a nota do Saresp os alunos têm seu desempenho classificado em quatro níveis de proficiência definidos com base nas expectativas de aprendizagem da Proposta Pedagógica do Estado de São Paulo. (São Paulo, 2010)

A Tabela 1 apresenta a descrição e os valores de referência dos níveis de desempenho destas proficiências na disciplina de Matemática. Destaca-se que estes níveis de proficiência são válidos para os ensinos fundamental e médio. 
Tabela 1. Descrição níveis de desempenho Saresp.

\begin{tabular}{|c|c|c|c|}
\hline \multirow{2}{*}{$\begin{array}{l}\text { Níveis de } \\
\text { Desempenho }\end{array}$} & \multirow{2}{*}{ Descrição } & \multicolumn{2}{|c|}{ Valores de referência } \\
\hline & & $\begin{array}{l}9^{\circ} \quad \text { Ano } \\
\text { Ensino } \\
\text { Fundamental }\end{array}$ & $\begin{array}{l}3^{\circ} \\
\text { Série } \\
\text { Ensino } \\
\text { Médio }\end{array}$ \\
\hline $\begin{array}{l}\text { Abaixo do } \\
\text { básico }\end{array}$ & $\begin{array}{l}\text { Demonstram domínio insuficiente dos } \\
\text { conteúdos, competências e habilidades } \\
\text { requeridos para a série escolar em que se } \\
\text { encontram }\end{array}$ & $<225$ & $<275$ \\
\hline Básico & $\begin{array}{l}\text { Demonstram desenvolvimento parcial } \\
\text { dos conteúdos, competências e } \\
\text { habilidades requeridos para a série } \\
\text { escolar em que se encontram }\end{array}$ & $\begin{array}{l}\text { Entre } 225 \text { e } \\
300\end{array}$ & $\begin{array}{l}\text { Entre } \\
275 \text { e } \\
350\end{array}$ \\
\hline Adequado & $\begin{array}{l}\text { Demonstram conhecimento e domínio } \\
\text { dos conteúdos, competências e } \\
\text { habilidades requeridos para a série } \\
\text { escolar em que se encontram }\end{array}$ & $\begin{array}{l}\text { Entre } 300 \text { e } \\
350\end{array}$ & $\begin{array}{l}\text { Entre } \\
350 \text { e } \\
400\end{array}$ \\
\hline Avançado & $\begin{array}{l}\text { Demonstram conhecimento e domínio } \\
\text { dos conteúdos, competências e } \\
\text { habilidades além dos requeridos para a } \\
\text { série escolar em que se encontram }\end{array}$ & $>350$ & $>400$ \\
\hline
\end{tabular}

Fonte: Adaptado São Paulo, 2010.

O resultado do Saresp é base para o cálculo do Idesp, indicador criado no ano de 2007 para medir a qualidade do ensino na rede estadual paulista, que é um índice que considera os resultados do Saresp e o fluxo escolar, que é composto pelas taxas de aprovação, reprovação e abandono dos alunos da unidade escolar. (SÃO PAULO, 2020 (a)) 
A divulgação pública dos índices do Idesp e dos indicadores de níveis de proficiência do Saresp é uma forma de responsabilizar todos os envolvidos no desempenho dos alunos, despertar o interesse em contribuir e potencialmente criar formas e incentivos para melhoria do desempenho, com ações governamentais, maior participação dos pais e da comunidade escolar. (VELOSO, 2009; OSHIRO; SCORZAFAVE, 2011)

Através destes índices educacionais, a educação tornou-se uma variável mensurável onde indicadores estatísticos permitem a conclusão, muitas vezes equivocada, de que um maior índice reflete em sucesso educacional. É necessário aplicar ao conceito de qualidade educacional, não apenas um valor numérico, mas também os fatores ideológicos, políticos e sociais a que toda comunidade escolar esteja inserida. (UNESCO, 2007; GESQUI, 2014)

Sem esta premissa de contextualizar a comunidade escolar, a divulgação pública dos resultados de avaliações externas e padronizadas para toda a rede funciona como uma forma de responsabilizar as escolas e seus funcionários pelo desempenho dos alunos e, desta forma, criar incentivos para melhoria. Pressupõem-se com isso uma maior participação dos pais para melhoria dos resultados e também o oferecimento de premiações ou "sansões punitivas" em face ao desempenho em exames (VELOSO, 2009).

A pressão para a melhora dos níveis de desempenho sobre os professores é maior por parte da gestão (supervisor de ensino, diretor, vice-diretor e coordenador) e em pequena parcela pelos pais que responsabilizam os professores pelo sucesso de seus filhos. Ao analisar a escola, alunos e professores, alguns membros do corpo docente culpam os professores das disciplinas de Matemática e Língua Portuguesa pelo baixo desempenho. Já alguns alunos culpam diretamente os professores pelos seus resultados pessoais. (GESQUI, 2014)

Assim, os professores de Matemática e Língua Portuguesa, que são as disciplinas analisadas no Saresp, são os principais atores ao terem suas funções e desempenho analisados e julgados por seus superiores, pares e comunidade escolar. Toda a equipe gestora e corpo docente preocupam-se mais com a repercussão da divulgação 
dos resultados dos níveis de proficiência do que com as boas práticas pedagógicas aplicadas ao longo do processo de aprendizagem. (GESQUI, 2014)

Nestas condições novas ações e intervenções são realizadas a cada ano para que as escolas melhorem o desempenho dos seus alunos. A implantação das avaliações ADE e AAP são exemplos destas ações visando o êxito de toda a rede, bem como alguns treinamentos ao corpo docente das disciplinas do Saresp e fornecimento de material de apoio, apostila Caderno do Aluno, padronizado para toda a rede.

Portanto, o objetivo geral deste trabalho é analisar os níveis de proficiência na disciplina de Matemática, no período entre 2014 e 2018, de quatro escolas estaduais do município de Mogi Mirim, no $9^{\circ}$ Ano do Ensino Fundamental e na $3^{\circ}$ Série do Ensino Médio, contextualizando este desempenho com questões ligadas a localização da escola, equipe gestora, corpo docente e discente e participação da comunidade escolar no cotidiano escolar.

\section{DESENVOLVIMENTO}

Esta pesquisa baseou-se na análise do nível de desempenho e proficiência na disciplina de Matemática obtidos na avaliação do Saresp, em quatro escolas estaduais no município de Mogi Mirim, interior do estado de São Paulo, integrantes da Diretoria de Ensino da Região de Mogi Mirim - DE Mogi Mirim.

$\mathrm{Na}$ Figura 1 tem-se a localização destas escolas e o raio de abrangência dos alunos, com a Escola A concentrando mais alunos das Zonas Sul e Oeste, além de muitos alunos da zona rural e por estar localizada na região central da cidade acaba recebendo alunos de toda a cidade.

A Escola B tem predominância de alunos da região Central e começo das áreas periféricas. Já as escolas C e D são escolas da periferia de Mogi Mirim, localizando na Zona Leste a Escola C e na Zona Norte a Escola D 
Figura 1. Raio de localização média da residência dos alunos nas escolas analisadas.

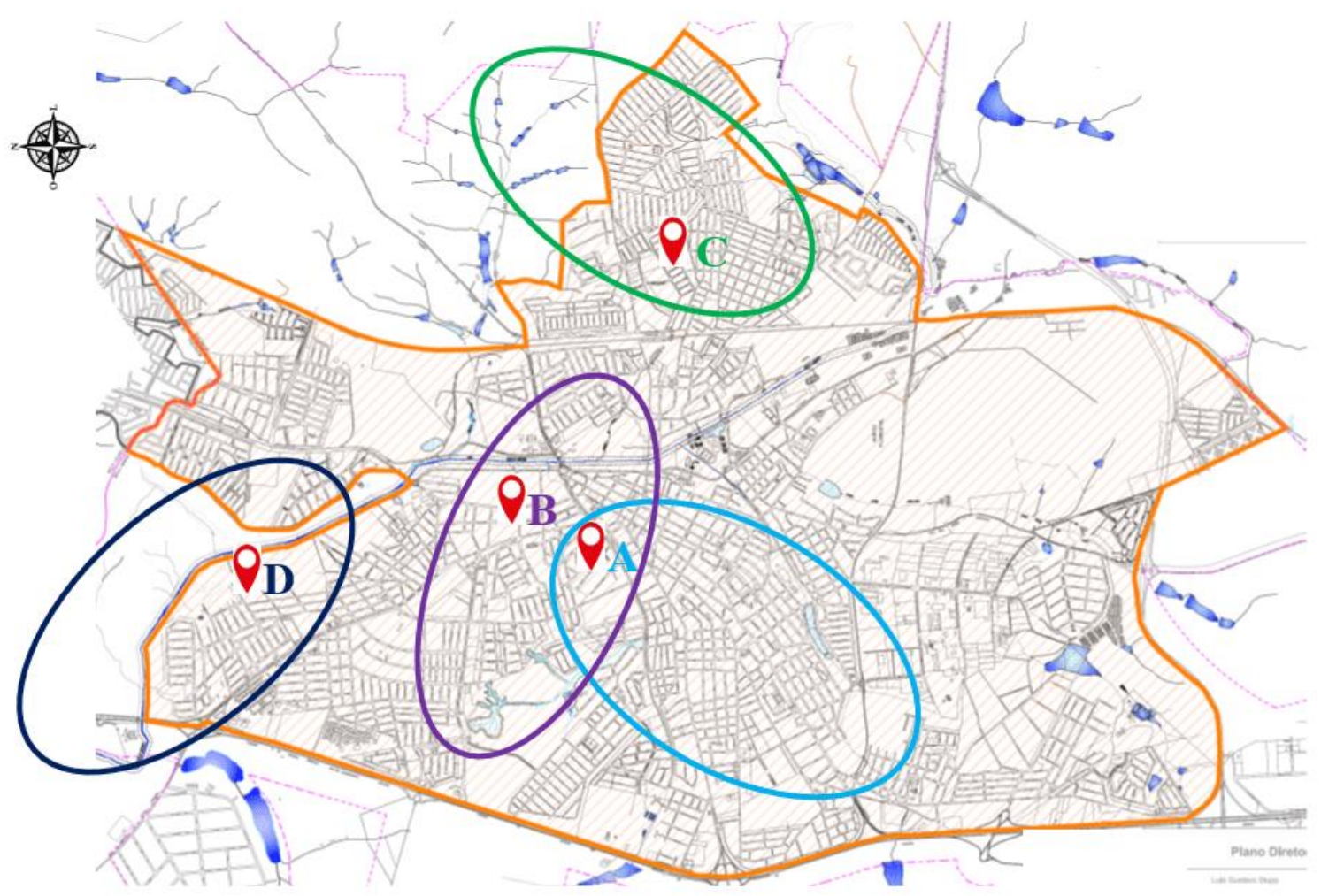

Fonte: Mapa disponível em Mogi Mirim (2015). Arte do autor

$\mathrm{Na}$ Figura 2 tem-se a ilustração do desempenho na disciplina de Matemática para o $9^{\circ}$ Ano do Ensino Fundamental, sendo Figura 2 (a), Escola A, Escola B Figura 2 (b), Figura 2 (c) Escola C e Escola D Figura 2 (d). 
Figura 2. Desempenho em Matemática, $9^{\circ}$ Ano Ensino Fundamental, Escola A (a), Escola B (b), Escola C (c), Escola D (d).

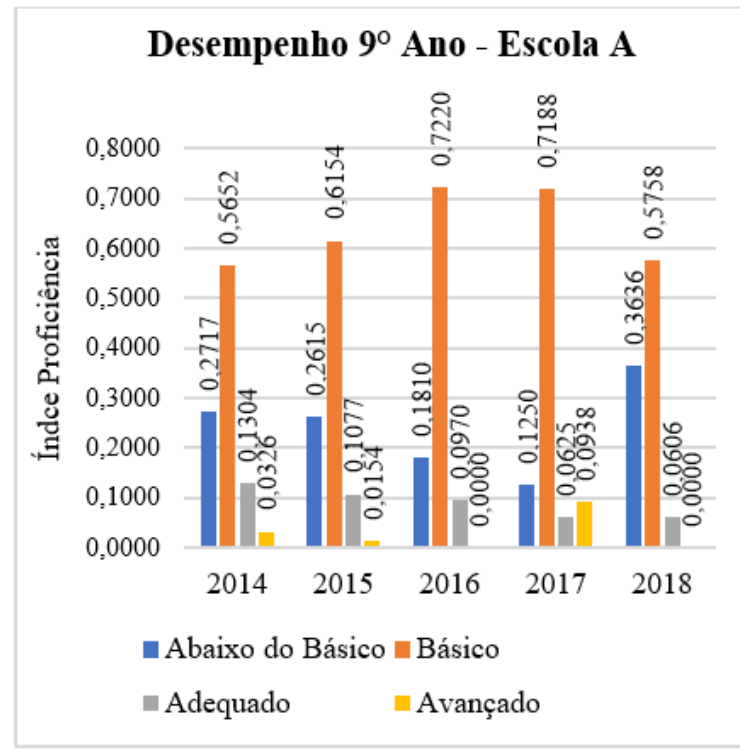

(a)

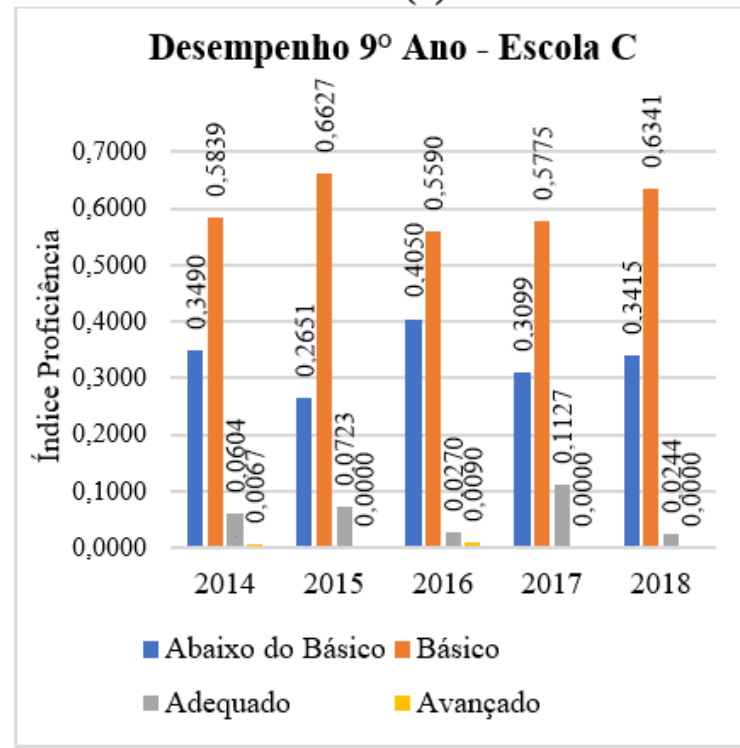

(c)

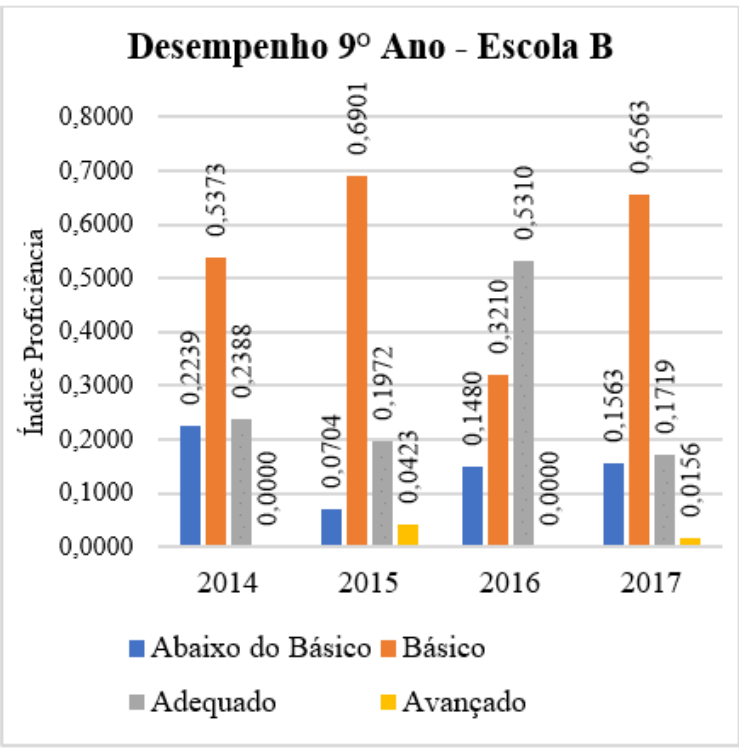

(b)

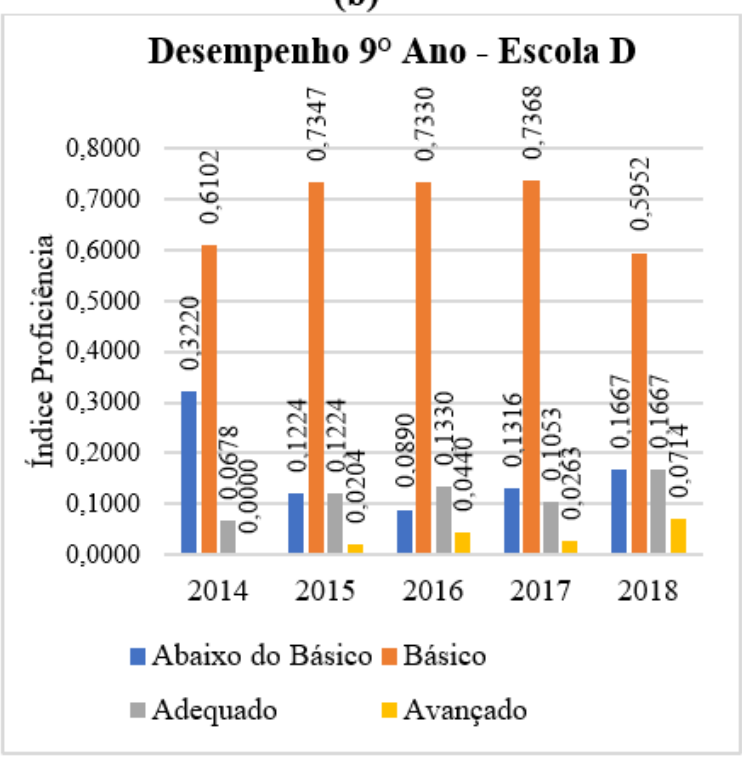

(d)

Fonte: Elaboração do autor. Resultados disponíveis em São Paulo, 2020 (b).

Observa-se em todas as escolas analisadas que a maioria dos alunos tem seu desempenho em Matemática classificado no nível de proficiência "Básico", isto é, nas avaliações do Saresp, no período entre 2014 a 2018, os alunos demonstraram 
desenvolvimento parcial dos conteúdos, competências e habilidades requeridos para a série escolar em que se encontram.

De um modo geral, é pequeno o desempenho nos níveis "Adequado" ou "Avançado". A maior porcentagem dos alunos da Escola A possuem níveis de desempenho de "Abaixo do Básico" e "Básico", indicando que os alunos não desenvolveram totalmente os conteúdos, competências e habilidades para o período escolar avaliado.

A Escola B apresentou variação não linear entre os níveis de desempenho, porém, é a escola com maior quantidade de alunos no nível "Adequado", isto é, alguns de seus alunos demonstram conhecimento e domínio dos conteúdos, competências e habilidades requeridos para a série escolar em que se encontram.

Com maior porcentagem de proficiência no nível "Abaixo do básico", os alunos da Escola C demonstram domínio insuficiente dos conteúdos, competências e habilidades requeridos para a série escolar em que se encontram.

$\mathrm{Na}$ escola $\mathrm{D}$, mesmo sendo escola do Programa de Ensino Integral - PEI, a maior quantidade dos alunos possuem nível "Básico" de proficiência em Matemática, isto é, seus alunos demonstram desenvolvimento parcial dos conteúdos, competências e habilidades requeridos para a série escolar em que se encontram, fato que não condiz com as características da escola PEI, que tende a ter um ensino mais eficiente que as escolas que não fazem parte deste programa.

O desempenho em Matemática para a $3^{\circ}$ Série do Ensino Médio da Escola A é apresentado na Figura 3 (a), da Escola B na Figura 3 (b) e na Figura 3 (c) tem-se 0 desempenho da Escola C. A Escola D não oferece o ensino médio.

Diferentemente do desempenho no $9^{\circ}$ Ano do Ensino Fundamental, a Escola A, na $3^{\circ}$ Série do Ensino Médio, tem grande parcela de seus de alunos com conhecimento em Matemática classificado como "Abaixo do básico", isto é, demonstram domínio insuficiente dos conteúdos, competências e habilidades requeridos para a série escolar em que se encontram. Entretanto, nos dois últimos anos analisados, $2017 \mathrm{e}$ 2018, aumentou a quantidade de alunos com conhecimento "Básico". 
A Escola $B$ apresenta maior parcela dos seus alunos da $3^{\circ}$ série do ensino médio com conhecimento "Básico" em Matemática indicando desenvolvimento parcial dos conteúdos, competências e habilidades requeridos para a série escolar em que se encontram. Para o ano de 2018, a escola passou a funcionar na modalidade PEI, fator este que contribuiu para o aumento de alunos com conhecimento "Adequado", isto é, os alunos demonstram conhecimento e domínio dos conteúdos, competências e habilidades requeridos para a série escolar em que se encontram.

A Escola C, novamente, é a que apresenta o pior desempenho em Matemática, sendo que a maioria dos seus alunos da $3^{\circ}$ série do ensino médio tem conhecimento "Abaixo do básico", isto é, demonstram domínio insuficiente dos conteúdos, competências e habilidades requeridos para a série escolar em que se encontram. A Escola D não oferece a modalidade de ensino médio. 
Figura 3. Desempenho em Matemática, $3^{\circ}$ Série Ensino Médio, Escola A (a), Escola B (b), Escola C (c).

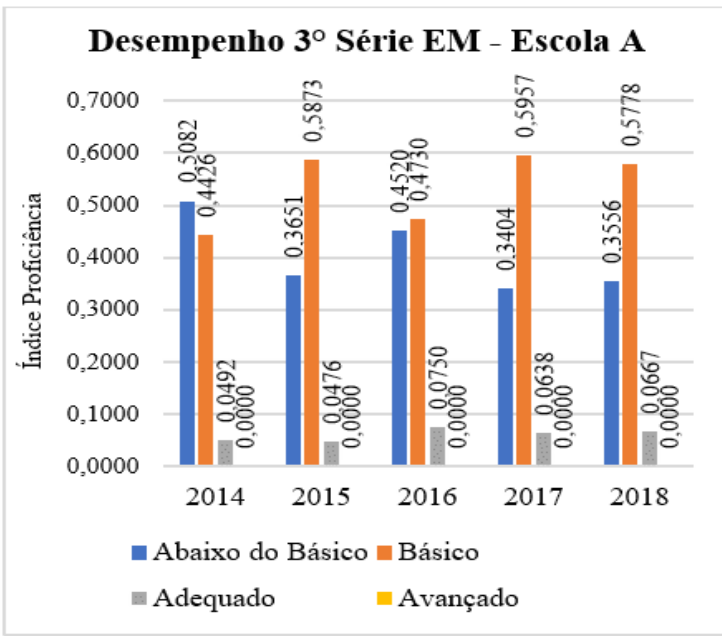

(a)

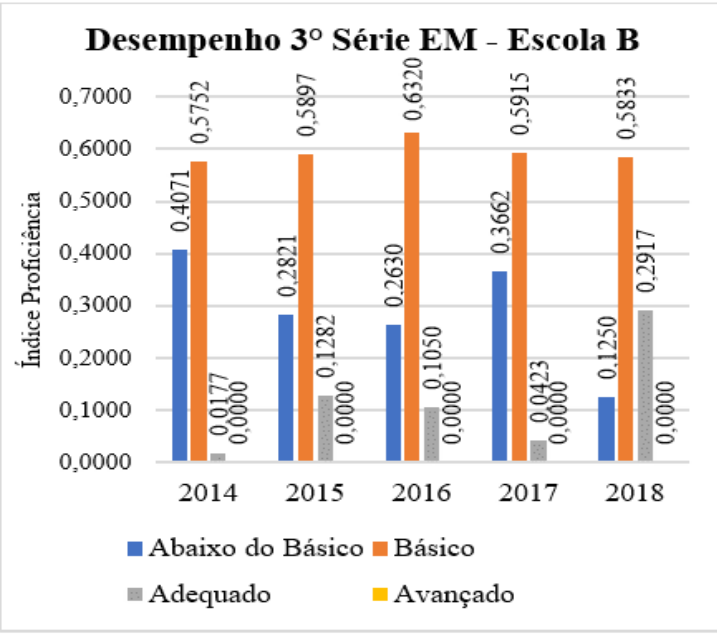

(b)

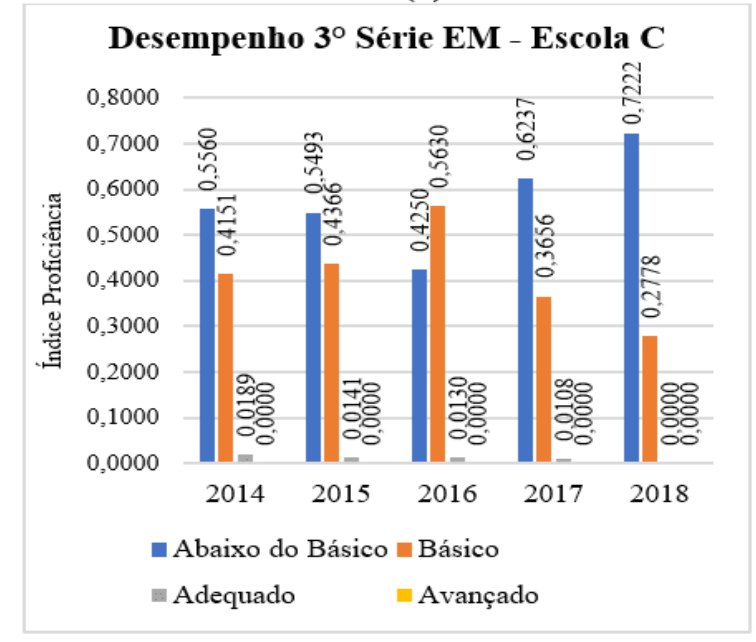

(c)

Fonte: Elaboração do autor. Resultados disponíveis em São Paulo, 2020 (b).

Um fato a destacar em todas as escolas analisadas na $3^{\circ}$ Série do Ensino Médio é a inexistência de alunos com conhecimento "Avançado" em Matemática, ou seja, nenhum aluno das três escolas analisadas no período de 2014 a 2018 demonstram conhecimento e domínio dos conteúdos, competências e habilidades além dos requeridos para a série escolar em que se encontram, o que indica uma potencial defasagem de conhecimento não apenas para a avaliação em si, mas para a continuidade de seus estudos em nível técnico e/ou superior. 
É de conhecimento público que os alunos do ensino médio apresentam maior defasagens de aprendizado comparado ao desempenho do ensino fundamental, além de maiores índices de evasão e abandono escolar.

Aliado a estes fatores tem-se o ensino médio muitas vezes oferecido nos períodos matutino, com cinco aulas semanais de Matemática, e noturno, com quatro aulas semanais. Com isso tem-se uma diferença de $20 \%$ na carga horária para a mesma série, o que já pode comprometer o ensino e muitas vezes desestimular o aluno para estudar mais e alcançar melhores níveis de desempenho nas avaliações.

Por ser oferecido em dois turnos distintos, o ensino médio apresenta maior rotatividade de alunos entre os períodos, devido a busca de qualificação profissional e emprego, contribuindo também para o aumento dos índices de evasão e abandono escolar.

Muitas escolas estaduais enfrentam questões ligadas à mudanças constantes da equipe gestora da escola, não tendo sequência as ações das gestões anteriores, com cada qual em pouco tempo de serviço querendo imprimir sua marca, mas sem analisar e continuar o que estava dando resultado.

Soma-se também a grande rotatividade do corpo docente, devido a falta de professores efetivos e as políticas públicas de contratação de professores temporários. Já o corpo discente das escolas estaduais é marcado por alunos com diferentes níveis sócios-econômicos, desde aqueles com potenciais condições de vulnerabilidade social até famílias de classe média.

Portanto, a soma de todos estes fatores compromete a qualidade de ensino das escolas estaduais paulista refletindo no desempenho em Matemática verificado nas avaliações do Saresp. Assim, a melhoria de desempenho não se restringe ao comprometimento dos alunos durantes os estudos e realizações das avaliações, são necessárias ações sociais para toda a comunidade escolar, equipe gestora e corpo docente estáveis e apoio da Seduc-SP para condução do seu trabalho para que esta situação se reverta, isto é, tenhamos mais alunos com nível de desempenho 
"Adequado" e "Avançado" na disciplina de Matemática, para o $9^{\circ}$ Ano do Ensino Fundamental e $3^{\circ}$ Série do Ensino Médio.

\section{CONCLUSÃO}

Uma análise inicial dos níveis de desempenho na disciplina de Matemática, em escolas públicas do estado de São Paulo, permite atribuir, na inicial, os baixos níveis de desempenho a ausência de controle nas ações e metas por parte da equipe gestora, acompanhada de falta de empenho do corpo docente e de comprometimento dos alunos.

Entretanto, há de considerar vários fatores que influenciaram estes baixos níveis de desempenho em Matemática para o $9^{\circ}$ Ano do Ensino Fundamental e para a $3^{\circ}$ Série do Ensino Médio, não apenas para as escolas analisadas, mas no contexto de nível estadual. Não se pode simplesmente responsabilizar os professores e a gestão escolar pelo desempenho dos alunos é necessária uma explanação macro para verificar as razões destes resultados.

Com base em estudos anteriores permite-se acrescentar algumas considerações referentes a estes fatores. A escola pública estadual paulista figura atualmente como local para manter os alunos por no mínimo $75 \%$ do ano letivo e que estes realizem as avaliações externas quando solicitadas.

Aliam-se a estes fatores a potencial apatia de pequena parcela de gestores e docentes em aplicar novos métodos, técnicas e procedimentos que resultem em um processo de ensino e aprendizagem eficaz frente ao simples treinamento e "adestramento" para a realização destas avaliações, AAP, ADE e Saresp, por exemplo. (GESQUI, 2014)

Tal apatia está ligada ao descaso, a nível nacional com a educação básica pública, refletindo em baixa renumeração aos profissionais, impossibilidade dos gestores em selecionar seu corpo docente e, principalmente, os alunos, pois o sistema de matrícula é estritamente de caráter geográfico, isto é, o aluno tem que ser matriculado na escola 
mais perto de sua casa. E não há mecanismo ou legislação que impeça uma escola pública em aceitar ou recusar um aluno.

A localização da escola e seu corpo discente acarreta maior troca de professores e gestão nas escolas periféricas e com consequentes menores níveis de desempenho em avaliações como o Saresp, ficando aqueles com mais tempo de serviço melhores classificados e portanto, tendo preferência, tanto no momento da remoção, para o quadro de efetivos, como no momento da escolha de aulas para os não efetivos.

Com isso, a rotatividade de professores entre as escolas estaduais paulista é elevada, ficando os professores com menor experiência na docência em escolas mais periféricas, que possuem, em sua maioria, menores níveis de desempenho, conforme pode ser verificado nesta análise com os resultados da Escola C.

A própria falta de autonomia da equipe de atribuição de aula em nível regional, Diretoria de Ensino, e da gestão em aceitar ou recusar um professor já é um fator para que a educação não funcione como uma estrutura gerencial passível de correção de imprevistos e maus resultados. (TAVARES, 2012)

Porém, o corpo efetivo estável e experiente não é garantia de melhores resultados. Estes professores estimulam e sabem contornar imprevistos, trabalhar com adversidades e principalmente conhecem os tipos de provas analisadas, porém, há necessidade de um maior comprometimento dos alunos durante todo o ano letivo $e$ maior engajamento e responsabilidade nas realizações das avaliações.

Considerando-se a aplicação de avaliações padronizadas pela Seduc-SP, ADE, AAP e Saresp, a educação púbica paulista é cada vez mais pontuada em índices numéricos padronizados, caso dos níveis de desempenho em Matemática analisados neste trabalho. Índices estes que permitem nortear ações e planos educacionais, pressionando os profissionais para o cumprimento de metas, porém, em muitos casos estes resultados não são considerados por parte da gestão e professores na condução de seus trabalhos, o que poderia resultar em melhora da aprendizagem dos alunos. (GESQUI, 2014) 
Analisando os níveis de desempenho na disciplina de Matemática, com base nos resultados da avaliação do Saresp, no período de 2014 a 2018 em quatro escolas estaduais do município de Mogi Mirim, Diretoria de Ensino de Mogi Mirim, nos ensinos fundamental anos finais ( $9^{\circ}$ ano) e $3^{\circ}$ série do ensino médio, os resultados ilustram um baixo nível de proficiência dos alunos.

A grande maioria dos alunos do $9^{\circ}$ Ano do Ensino Fundamental apresenta desempenho "Básico" na disciplina de Matemática, isto é, os alunos demonstram desenvolvimento parcial dos conteúdos, competências e habilidades requeridos para a série escolar em que se encontram.

Para a $3^{\circ}$ Série do Ensino Médio o nível de desempenho "Abaixo do básico", que é aquele em que os alunos demonstram domínio insuficiente dos conteúdos, competências e habilidades requeridos para a série escolar em que se encontram, atingiu parcela considerável do alunado, o que demonstra que a aprendizagem destes alunos não está sendo adequada para sua formação básica escolar e prosseguimento dos estudos.

Portanto, os níveis de desempenho em Matemática, não somente aqui analisados nas em toda a rede pública paulista, demostram que a Seduc-SP precisa desenvolver ações para melhoria da aprendizagem, com equipe gestora e corpo docente acatando estas metodologias e adaptando-as a realidade da localização da unidade escolar e principalmente que haja maior comprometimento dos alunos e comunidade escolar, para reverter estes níveis de desempenho, tendo cada vez mais alunos em níveis "Adequado" e "Avançado", o que será resultado de uma educação pública de qualidade, que é o que todos os envolvidos anseiam.

\section{REFERÊNCIAS}

GESQUI, L. C. A gestão escolar refém dos resultados das avaliações externas em larga escala. Revista de Ciências Humanas - Educação, Frederico Westphalen-RS. v. 15, n. 25, Dez. 2014 
MOGI MIRIM. Revisão do Plano Diretor de Mogi Mirim. 2015. Disponível em: https://consulta.siscam.com.br/camaramogimirim/Documentos/Documento/36705. Acesso em: 27/04/2020.

OSHIRO, C. H.; SCORZAFAVE, L. G. Efeito do pagamento de bônus aos professores sobre a proficiência escolar no estado de São Paulo. Encontro Anpec - 2011. Disponível em: https://www.anpec.org.br/encontro/2011/inscricao/arquivos/000e95d077296d03faa27e429dc66192da8.pdf. Acesso em: 24/04/2020.

SÃO PAULO. Programa de Qualidade da Escola - Sumário Executivo Março/2010. Disponível em: http://idesp.edunet.sp.gov.br/Arquivos/Nota_tecnica_2009.pdf. Acesso em: 21/04/2020.

SÃO PAULO. Idesp 2019 mostra evolução dos alunos do Ensino Fundamental da rede paulista. Disponível em: https://www.saopaulo.sp.gov.br/spnoticias/idesp-2019mostra-evolucao-dos-alunos-do-ensino-fundamental-da-rede-estadual-de-sp/. Acesso em: 21/04/2020. (a)

SÃO PAULO. Índices Idesp. Disponível em: http://idesp.edunet.sp.gov.br/. Aceso em: 30/04/2020. (b)

TAVARES, P. A. Os impactos de práticas de gestão escolar sobre o desempenho educacional: evidências para escolas estaduais paulistas. In: Textos para Discussão da Escola de Economia de São Paulo da Fundação Getulio Vargas - FGV-EESP. Julho, 2012.

UNESCO. Educação de qualidade para todos: um assunto de direitos humanos. Brasília: Unescol Orelac. 2007.138p.

VELOSO, F. Experiências de Reforma Educacional nas Últimas Duas Décadas: o que Podemos Aprender?. In: VELOSO, F. (Org), Educação Básica no Brasil. Rio de Janeiro: Elsevier, 2009. 
Enviado: Outubro, 2020.

Aprovado: Novembro, 2020. 